\title{
MicroRNA-182 modulates chemosensitivity of human non-small cell lung cancer to cisplatin by targeting PDCD4
}

Fang-ling Ning, Feng Wang, Mian-li Li, Ze-shun Yu, Yan-zhang Hao and Shao-shui Chen*

\begin{abstract}
Background: Overexpression of microRNA-182 (miR-182) is found in various human cancers, including non-small cell lung cancer (NSCLC). Our aim is to investigate the association of miR-182 expression with the sensitivity of NSCLC to cisplatin.

Methods: TaqMan RT-PCR or Western blot assay was performed to detect the expression of mature miR-182 and programmed cell death 4 (PDCD4) protein. miR-182 and (or) PDCD4 depleted cell lines were generated using miR-182 inhibitor and (or) siRNA. The viabilities of treated cells were analyzed using MTT assay.

Results: The expression level of miR-182 in A549 cell line was significantly higher than that in NHBE cell line $(p<0.01)$. Transfection of miR-182 inhibitor induced sensitivity of A549 cells to cisplatin. A549 cells transfected with PDCD4 siRNA became more resistant to cisplatin therapy. We found an increase PDCD4 protein level following the transfection of miR-182 inhibitor using Western blot analysis. In addition, the enhanced growth-inhibitory effect by miR-182 inhibitor was weakened after the addition of PDCD4 siRNA.
\end{abstract}

Conclusions: The results of the present study demonstrated that overexpression of miR-182 may involve in chemoresistance of NSCLC cells to cisplatin by down-regulating PDCD4.

Virtual Slides: The virtual slide(s) for this article can be found here: http://www.diagnosticpathology.diagnomx.eu/ vs/1793467320130186

Keywords: miRNA, PDCD4, miR-182, Chemosensitivity, A549, NSCLC

\section{Background}

Lung cancer is the most common cancer in the world, with a survival rate of $15 \%$ [1]. Approximately 1.6 million cases of lung cancer have occurred in 2008, of which $80 \%$ were non-small cell lung cancer (NSCLC). Surgical resection is known as the most effective treatment for NSCLC, however, due to the fact that most diagnoses were confirmed in an advanced stage, only a few patients can be cured by surgical treatment. Patients with NSCLC are mostly treated with platinum-based chemotherapy. However, the development of chemoresistance is a major obstacle limiting successful treatment [2]. Methods for improving chemotherapy and reducing

\footnotetext{
* Correspondence: bz_chenshaoshui@126.com

Department of Oncology, Binzhou Medical College Affiliated Hospital, 661\#, Yellow-River Second Street, 256603 Binzhou, Shandong Province, China
}

chemoresistance are accordingly of great interest in lung cancer chemotherapy [3,4].

MicroRNAs (miRNAs) are small non-coding RNAs of $20 \sim 22$ nucleotides. It represses gene expression through interaction with 3'untranslated regions (UTRs) of mRNAs. miRNAs are predicted to target over $50 \%$ of all human protein-coding genes, enabling them to have numerous regulatory roles in many physiological and developmental processes, including development, differentiation, apoptosis and proliferation, through imperfect pairing with target mRNAs of protein-coding genes and the transcriptional or post-transcriptional regulation of their expression [5,6]. miR-182 is one of the miRNAs often seen upregulated in cancers. Several studies have reported miR-182 to be upregulated in NSCLC [7]. Furthermore, miR-182 functions as an oncomiR to enhance cancer cell proliferation $[8,9]$. Recent studies indicated that 
miR-182 plays an important role in drug resistance. Husted et al. found that miR-182 was consistently upregulated in the multidrug resistant Ehrlich ascites tumor cells [10]. Therefore, we hypothesized that the up-regulation of miR-182 may be related to chemotherapy resistance in NSCLC, but the molecular mechanism remains unclear.

As an important tumor suppressor, programmed cell death 4 (PDCD4) influences transcription and translation of multiple genes, and modulates different signal transduction pathways. However, the upstream regulation of this gene is largely unknown. Until now, the mainly identified miRNA that directly targets PDCD4 is microRNA-21 (miR-21). MiR-21 has been found to negatively regulate PDCD4 expression in breast cancer, colorectal cancer, and ovarian cancer [11-13]. However, other potential PDCD4-targeting miRNAs remains to be defined. We speculate that miR-182 may play an important role in chemoresistance of A549 cells by downregulating the PDCD4.

\section{Methods \\ Cell line}

The Human Research Ethics Committee of Binzhou Medical College Affiliated Hospital approved this study. The human lung adenocarcinoma cell line A549 was purchased from the Cell Bank of Chinese Academy of Sciences (Shanghai, China). A549 cell line was cultured in DMEM containing 10\% fetal bovine serum (Gibco ${ }^{\circ}$, Invitrogen, Carlsbad, CA, USA), 100 units $/ \mathrm{ml}$ penicillin, and $100 \mu \mathrm{g} / \mathrm{ml}$ streptomycin at $37^{\circ} \mathrm{C}$ in a $5 \% \mathrm{CO} 2$ humidified incubator to the log phase of proliferation before harvesting the cells. Normal human bronchial epithelial cells $(\mathrm{NHBE})\left(\right.$ Clonetics $\left.^{\mathrm{TM}}\right)$ were maintained in a culture medium according to the protocol provided by Clonetics ${ }^{\mathrm{TM}}$.

\section{Drugs and reagents}

Cisplatin was purchased from QiLu Pharmaceutical (Jinan, China). MiR-182 inhibitor, PDCD4 siRNA, and their negative control oligonucleotides were obtained from Shanghai GeneChem Co., Ltd (Shanghai, China). These were used to transfect A549 cells using Lipofectamine $^{\mathrm{TM}} 2000$ (Invitrogen, Carlsbad, CA, USA) according to the instructions provided by the manufacturer. Monoclonal rabbit anti-human PDCD4 antibody (Cell Signaling Technology, Inc., Beverly, MA, USA) was used for Western blot analysis.

\section{MTT assay}

Cells transfected with miR-182 inhibitor or siRNA-PDCD4 were seeded into 96-well plates at $6 * 10^{3}$ cells/well and allowed to grow overnight, and then were treated with different concentrations of cisplatin. After $24 \mathrm{~h}$ of treatment, 20ul of $5 \mathrm{mg} / \mathrm{ml} \mathrm{MTT} \mathrm{reagent} \mathrm{(Sigma-Aldrich,} \mathrm{St.} \mathrm{Louis,}$
MO, USA) was added and incubated in the dark for $4 \mathrm{~h}$. The absorbance of the plate was measured in a microplate reader at a wavelength of a 570-nm reference (BMG Lab Technologies, Germany), and the results were expressed as the percentage of absorbance relative to untreated controls. Each treatment was carried out in triplicate.

\section{Real-time quantitative reverse transcription-PCR for miRNA expression and mRNA expression}

For miRNA expression detection, reverse transcription (RT) reaction was performed with PrimeScript ${ }^{\ominus} \mathrm{RT}$ reagent Kit (TAKARA BiotechnologyCO., LTD., Dalin, China) and realtime quantitative RT-PCR (qRT-PCR) was performed using SYBR ${ }^{\oplus}$ Premix Ex Taq $^{\text {TM }}$ II (TAKARA Biotechnology CO., LTD., Dalin, China) on the basis of the protocol provided by the manufacturer. For mRNA expression detection, reverse transcription reaction was performed with PrimeScript $^{\oplus}$ RT reagent Kit (TAKARA Biotechnology CO., LTD., Dalin, China) and RT-PCR (qRT-PCR) was performed using SYBR ${ }^{\odot}$ Premix Ex Taq $^{\mathrm{Tm}}$ II (TAKARA Biotechnology CO., LTD., Dalin, China). The designed PCR primers were as follows: PDCD4 forward primer, 5'-GGCCTCCAAGGAGTAAGACC-3'; PDCD4 reverse primer, 5'-AGGGGTCTACATGGCAA CTG-3'; GAPDH forward primer, 5'-AAGGGAAGGTT GCTGGATAGG-3'; GAPDH reverse primer, 5'-CACA TCCACCTCCTCCACATC-3'. The expression of the target miRNA was normalized relative to that of the internal control, U6 and the expression of the target gene was normalized relative to the expression of glyceraldehyde-3phosphate dehydrogenase (GAPDH), which was used as an internal control. Data were analyzed according to the comparative $\mathrm{Ct}$ method also referred to as the $2^{-\Delta \Delta \mathrm{CT}}$ method.

\section{Western blot assay}

The proteins were resolved on an SDS denaturing polyacrylamide gel and then transferred onto a nitrocellulose membrane. Antibody to PDCD4 or GAPDH was incubated with the membranes overnight at $4^{\circ} \mathrm{C}$. The membranes were washed and incubated with horseradish peroxidase (HRP)-conjugated secondary antibodies. Protein expression was assessed by enhanced chemiluminescence and exposure to chemiluminescent film. LabWorks ${ }^{\mathrm{TM}}$ Image Acquisition and Analysis Software (UVP, Upland, $\mathrm{CA}$ ) were used to quantify the band intensities. All the antibodies were purchased from Abcam (Cambridge, MA).

\section{Statistical analysis}

All the experiments were carried out in triplicate. The quantitative values were expressed as mean \pm standard deviation (SD), and the hypothesis test for significance between two groups utilized the Student's $t$ test. Statistical significance was set as $\mathrm{p}<0.05$. 


\section{Results}

MiR-182 was upregulated in human lung adenocarcinoma cell line A549

To define the role of miR-182 in human lung cancer tumorigenesis, we compared the expression levels of miR-182 in human lung cancer cell line A549 and NHBE cell line (normal human bronchial epithelial cells) by qRT-PCR. The expression level of miR-182 in A549 was significantly higher than that in NHBE cell line $(\mathrm{p}<0.01$, Figure 1).

\section{Transfection of miR-182 inhibitor induced sensitivity of A549 cells to cisplatin}

To further assess the effect of miR-182, we transfected miR-182 inhibitor and its negative control oligonucleotides into A549 cells. Transfection of cells with miR-182 inhibitor suppressed miR-182 level compared with the control cells (shown in Figure 2). The MTT assay showed that the miR-182-suppressed cells were significantly more sensitive to the therapy of cisplatin than control cells (shown in Figure 3).

\section{PDCD4 was a target of miR-182 and responsible for the} miR-182-induced resistance in A549 cells

We transfected A549 cells with miR-182 inhibitor or a scrambled miR-182 inhibitor control. The PDCD4 mRNA level was overexpression in miR-182-suppressed cells compared with controls (shown in Figure 4a). We examined the protein levels of PDCD4 following the transfection of miR-182 inhibitor in A549 cells by Western blot analysis and found that cells transfected with miR-182 inhibitor showed an increase PDCD4 protein expression (shown in Figure 4b). Down regulation of PDCD4 expression by siRNAs, A549 cells became more resistant to the therapy of cisplatin (shown in Figure 5). In addition, the enhanced growth-inhibitory effect by the miR-182

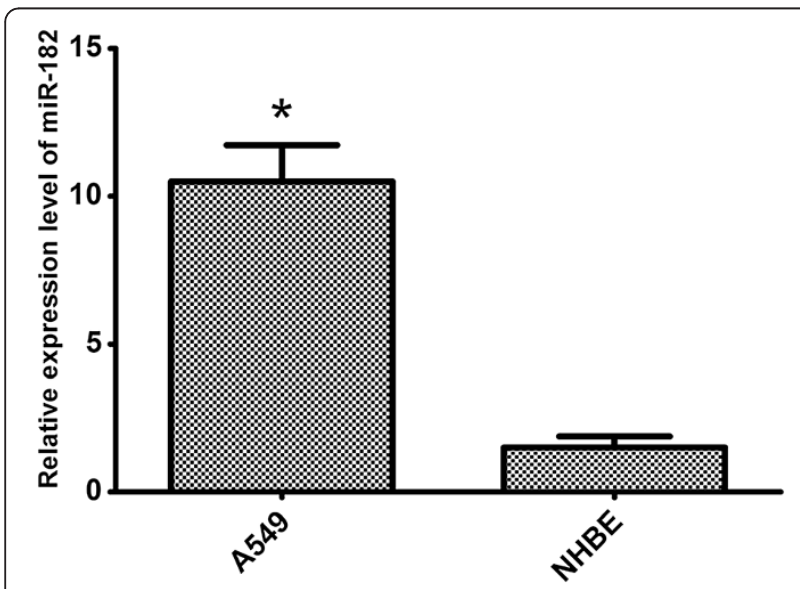

Figure 1 MiR-182 was up-regulated in A549 cell line compared to that in NHBE cell line $(p<0.01)$.

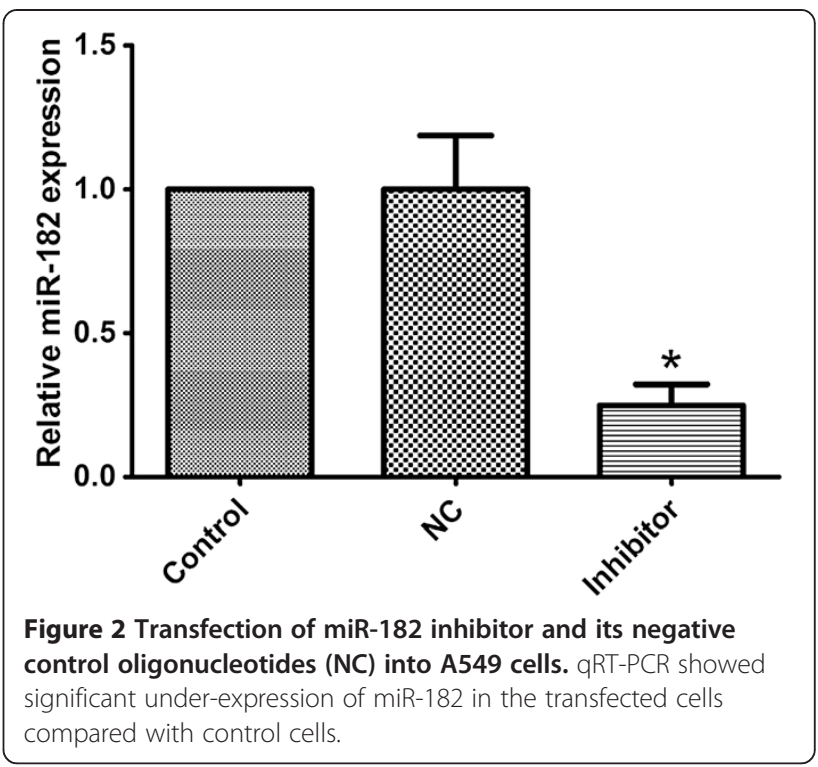

inhibitor transfection was weakened after the addition of PDCD4 siRNA (shown in Figure 5).

\section{Discussion}

Although chemotherapeutic agents are widely used in the treatment of lung cancer, their efficacy is often limited by the existence or development of chemoresistance. As one of the first-line chemotherapeutic agents for the treatment of NSCLC, cisplatin is a platinumbased compound that forms intra- and inter-strand adducts with DNA $[14,15]$. Despite tremendous efforts, cisplatin treatment often results in the development of drug resistance, leading to therapeutic failure, and the molecular mechanisms leading to cisplatin chemoresistance are poorly understood. Factors that enhance the

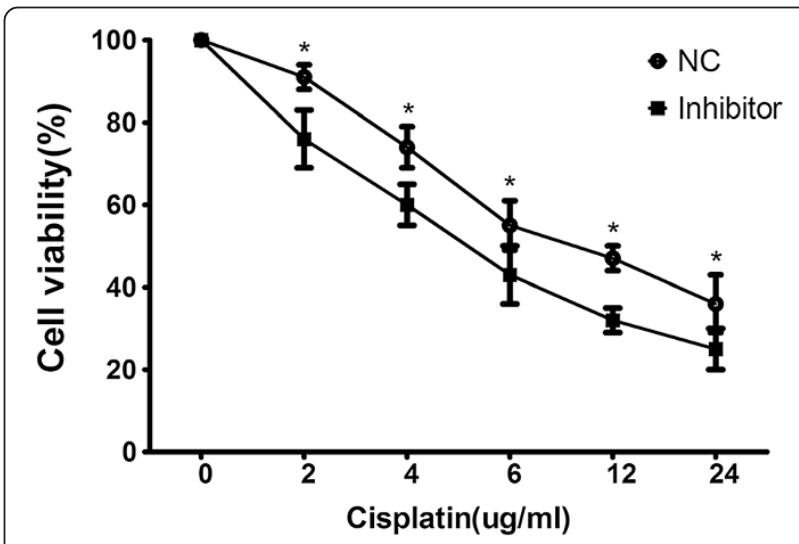

Figure 3 MTT assay revealed that the anti-tumour effects cisplatin in the miR-182 downregulated cells were significantly profound than in control cells $\left({ }^{*} \mathrm{P}<\mathbf{0 . 0 5}\right)$. Data are mean \pm SD of three experiments. 

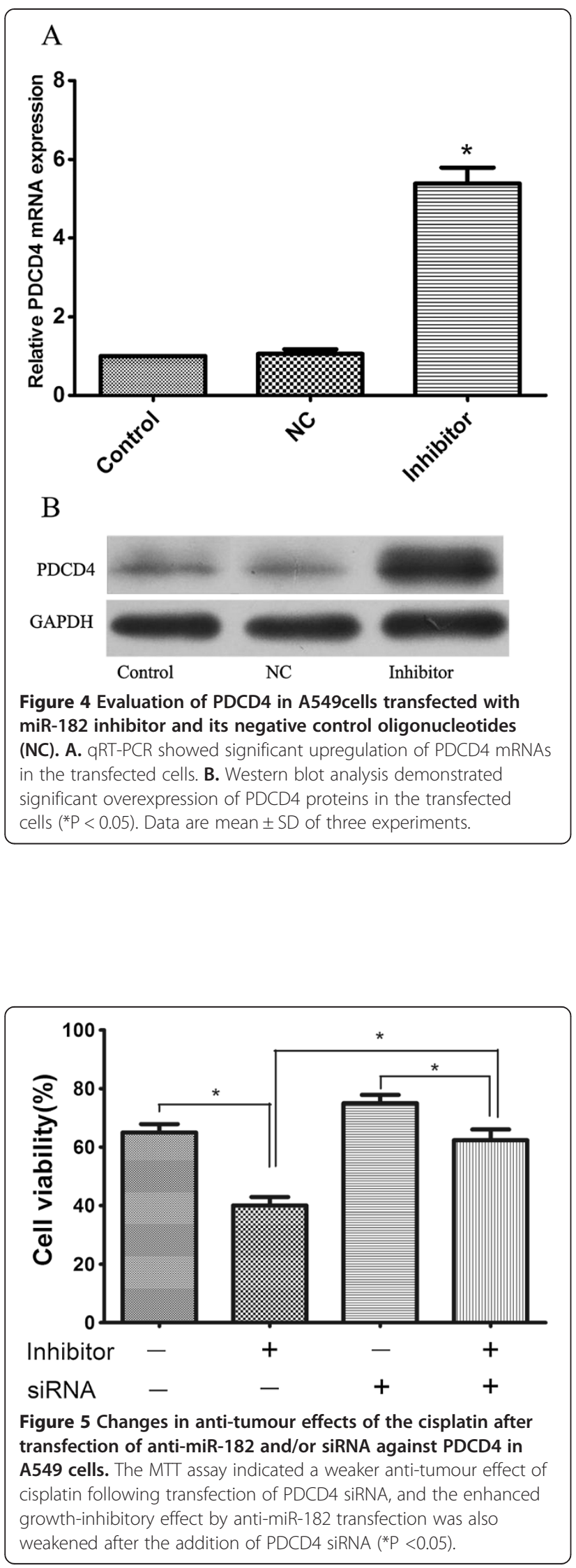

sensitivity of NSCLC cells to cisplatin may highlight predictive biomarkers or targets for therapy.

MiRNAs are thought to function as either tumor suppressors or oncogenes though target oncogenes or tumor suppressor genes during tumorigenesis and development of cancers [16-18]. miR-182 has been regarded as an oncogene in most contexts. In a cohort of 253 glioma patients, high miR-182 expression was found to be a negative prognostic factor [19]. In melanoma cell lines, Segura and coworkers showed that high miR-182 expression stimulated migration and survival. The same group treated liver metastases in mice with anti -miR-182 and obtained a lower tumor burden and a lower mir-182-level than in untreated mice [20]. Also in breast tumors and cervical cancers miR-182 seems to have an oncogenic impact $[21,22]$. Previously, Wang $M$ et al. found that miR182 was markedly upregulated in human lung cancer cells. They conducted MTT and colony formation assays to further evaluate the effect of miR-182 on lung cancer cell growth, and they performed transwell and wound healing assays to evaluate its role in regulating invasion and migration activity. Their results demonstrate that miR-182 acts as an oncogene in lung cancer [9].

Previous studies demonstrated that the acquired drug resistance of cancer cells is related to deregulation of miRNAs such as miR21, miR-503, miR-181a and miR620 [23-25]. In the present study, to explore whether the unregulated oncogene miR-182 was involved in the NSCLC cells resistant to cisplatin, we transfected miR182 inhibitor and its negative control oligonucleotides into A549 cells. Then MTT assay showed that the miR182-suppressed cells were significantly more sensitive to the therapy of cisplatin than control cells, indicating that overexpression of miR-182 may involve in chemoresistance of NSCLC cells to cisplatin.

In NSCLC tissues, many onco-miRs/tumor suppressortarget or tumor suppressor-miRs/onco-target pathways have been demonstrated to participate in the tumorigenesis of lung cancer, including miR7/BCL2 axis, miR-99b/ FGFR3 axis, miR-101/EZH2 axis, miR-192/RB1 axis and miR-196/HOXA5 axis [26-30]. However, miRNA/target network was so complex that more and more miRNA/target axis needs to be elucidated in lung cancer especially NSCLC. In the present study, We transfected A549 cells with miR-182 inhibitor or a scrambled miR-182 inhibitor control. The PDCD4 mRNA and protein were overexpression in miR-182-suppressed cells compared with controls, indicating that miR-182 was a negative regulator of PDCD4. Furthermore, we found that when down regulated of PDCD4 expression by siRNAs, A549 cells became more resistant to the therapy of cisplatin. In addition, the enhanced growth-inhibitory effect by the miR-182 inhibitor transfection was weakened after the addition of PDCD4 siRNA, suggesting that PDCD4 was 
responsible for the miR-182-induced resistance to cisplatin. These results established that miR-182 transfer in combination with cisplatin therapy may be a target to reverse chemotherapeutic resistance. In addition, further research is needed to investigate whether the expression level of miR-182 in tumor tissue and plasma might be used as a biomarker to predict platinum based chemotherapy response in patients with NSCLC.

\section{Conclusion}

In conclusion, the results of the present study demonstrates that overexpression of miR-182 may involve in chemoresistance of NSCLC cells to cisplatin by downregulating PDCD4. This finding suggests that inhibition of miR-182 may be a useful therapeutic strategy for NSCLC treatment.

\section{Competing interests}

The authors declare that they have no competing interests.

\section{Authors' contributions}

FLN, FW and SSC: conceived of the study, and participated in its design and coordination and helped to draft the manuscript. FLN, FW, MLL, ZSY and YZH: carried out part of experiments and wrote the manuscript. FLN, FW and MLL performed the statistical analysis. All authors read and approved the final manuscript.

Received: 19 May 2014 Accepted: 22 June 2014

Published: 10 July 2014

\section{References}

1. Siegel R, Ma J, Zou Z, Jemal A: Cancer statistics, 2014. CA Cancer J Clin 2014, 64(1):9-29.

2. Szakacs G, Paterson JK, Ludwig JA, Booth-Genthe C, Gottesman MM: Targeting multidrug resistance in cancer. Nat Rev Drug Discov 2006, 5(3):219-234.

3. Zheng S, Du Y, Chu H, Chen X, Li P, Wang Y, Ma Y, Wang H, Zang W, Zhang G, Zhao G: Analysis of MAT3 gene expression in NSCLC. Diagn Pathol 2013, 8:166.

4. Lu Q, Lu S, Huang L, Wang T, Wan Y, Zhou CX, Zhang C, Zhang Z, Li X: The expression of V-ATPase is associated with drug resistance and pathology of non-small-cell lung cancer. Diagn Pathol 2013, 8:145.

5. van Kouwenhove M, Kedde M, Agami R: MicroRNA regulation by RNAbinding proteins and its implications for cancer. Nat Rev Cancer 2011, 11(9):644-656

6. Calin GA, Croce CM: MicroRNA signatures in human cancers. Nat Rev Cancer 2006, 6(11):857-866

7. Guan P, Yin Z, Li X, Wu W, Zhou B: Meta-analysis of human lung cance microRNA expression profiling studies comparing cancer tissues with normal tissues. J Exp Clin Cancer Res 2012, 31:54.

8. Yang WB, Chen PH, Hsu TS, Fu TF, Su WC, Liaw H, Chang WC, Hung JJ: Sp1-mediated microRNA-182 expression regulates lung cancer progression. Oncotarget 2014, 5(3):740-753.

9. Wang $M$, Wang Y, Zang W, Wang H, Chu H, Li P, Li M, Zhang G, Zhao G: Downregulation of microRNA-182 inhibits cell growth and invasion by targeting programmed cell death 4 in human lung adenocarcinoma cells. Tumour Biol 2014, 35(1):39-46.

10. Husted S, Sokilde R, Rask L, Cirera S, Busk PK, Eriksen J, Litman T: MicroRNA expression profiles associated with development of drug resistance in Ehrlich ascites tumor cells. Mol Pharm 2011, 8(6):2055-2062.

11. Asangani IA, Rasheed SA, Nikolova DA, Leupold JH, Colburn NH, Post S, Allgayer H: MicroRNA-21 (miR-21) post-transcriptionally downregulates tumor suppressor Pdcd4 and stimulates invasion, intravasation and metastasis in colorectal cancer. Oncogene 2008, 27(15):2128-2136.

12. Wang $Y Q$, Guo RD, Guo RM, Sheng W, Yin LR: MicroRNA-182 promotes cell growth, invasion, and chemoresistance by targeting programmed cell death 4 (PDCD4) in human ovarian carcinomas. J Cell Biochem 2013, 114(7):1464-1473.

13. Zhu S, Wu H, Wu F, Nie D, Sheng S, Mo YY: MicroRNA-21 targets tumor suppressor genes in invasion and metastasis. Cell Res 2008, 18(3):350-359.

14. Judson I, Kelland LR: New developments and approaches in the platinum arena. Drugs 2000, 59(Suppl 4):29-36. discussion 37-28.

15. Reed JC: Mechanisms of apoptosis avoidance in cancer. Curr Opin Oncol 1999, 11(1):68-75.

16. Meng F, Glaser SS, Francis H, DeMorrow S, Han Y, Passarini JD, Stokes A, Cleary JP, Liu X, Venter J, Kumar P, Priester S, Hubble L, Staloch D, Sharma J, Liu CG, Alpini G: Functional analysis of microRNAs in human hepatocellular cancer stem cells. J Cell Mol Med 2012, 16(1):160-173.

17. Farazi TA, Spitzer Jl, Morozov $P$, Tuschl T: miRNAs in human cancer. J Pathol 2011, 223(2):102-115

18. Shah AA, Leidinger $P$, Blin N, Meese E: miRNA: small molecules as potential novel biomarkers in cancer. Curr Med Chem 2010, 17(36):4427-4432.

19. Jiang L, Mao P, Song L, Wu J, Huang J, Lin C, Yuan J, Qu L, Cheng SY, Li J: miR-182 as a prognostic marker for glioma progression and patient survival. Am J Pathol 2010, 177(1):29-38.

20. Segura MF, Hanniford D, Menendez S, Reavie L, Zou X, Alvarez-Diaz S, Zakrzewski J, Blochin E, Rose A, Bogunovic D, Polsky D, Wei J, Lee P, Belitskaya-Levy I, Bhardwaj N, Osman I, Hernando E: Aberrant miR-182 expression promotes melanoma metastasis by repressing $\mathrm{FOXO} 3$ and microphthalmia-associated transcription factor. Proc Natl Acad Sci USA 2009, 106(6):1814-1819.

21. Tang T, Wong HK, Gu W, Yu MY, To KF, Wang CC, Wong YF, Cheung TH, Chung TK, Choy KW: MicroRNA-182 plays an onco-miRNA role in cervical cancer. Gynecol Oncol 2013, 129(1):199-208.

22. Moskwa P, Buffa FM, Pan Y, Panchakshari R, Gottipati P, Muschel RJ, Beech J, Kulshrestha R, Abdelmohsen K, Weinstock DM, Gorospe M, Harris AL, Helleday T, Chowdhury D: miR-182-mediated downregulation of BRCA1 impacts DNA repair and sensitivity to PARP inhibitors. Mol Cell 2011, 41(2):210-220

23. Qiu T, Zhou L, Wang T, Xu J, Wang J, Chen W, Zhou X, Huang Z, Zhu W, Shu Y, Liu P: miR-503 regulates the resistance of non-small cell lung cancer cells to cisplatin by targeting Bcl-2. Int J Mol Med 2013, 32(3):593-598

24. Gao W, Lu X, Liu L, Xu J, Feng D, Shu Y: MiRNA-21: a biomarker predictive for platinum-based adjuvant chemotherapy response in patients with non-small cell lung cancer. Cancer Biol Ther 2012, 13(5):330-340.

25. Galluzzi L, Morselli E, Vitale I, Kepp O, Senovilla L, Criollo A, Servant N, Paccard C, Hupe P, Robert T, Ripoche H, Lazar V, Harel-Bellan A, Dessen P, Barillot $E$, Kroemer G: miR-181a and miR-630 regulate cisplatin-induced cancer cell death. Cancer Res 2010, 70(5):1793-1803.

26. Cho HM, Jeon HS, Lee SY, Jeong KJ, Park SY, Lee HY, Lee JU, Kim JH, Kwon SJ, Choi E, Na MJ, Kang J, Son JW: microRNA-101 inhibits lung cancer invasion through the regulation of enhancer of zeste homolog 2. Exp Ther Med 2011, 2(5):963-967.

27. Kang J, Lee SY, Lee SY, Kim YJ, Park JY, Kwon SJ, Na MJ, Lee EJ, Jeon HS, Son JW: microRNA-99b acts as a tumor suppressor in non-small cell lung cancer by directly targeting fibroblast growth factor receptor 3 . Exp Ther Med 2012, 3(1):149-153.

28. Liu XH, Lu KH, Wang KM, Sun M, Zhang EB, Yang JS, Yin DD, Liu ZL, Zhou J, Liu ZJ, De W, Wang ZX: MicroRNA-196a promotes non-small cell lung cancer cell proliferation and invasion through targeting HOXA5. BMC Cancer 2012, 12:348.

29. Feng S, Cong S, Zhang X, Bao X, Wang W, Li H, Wang Z, Wang G, Xu J, Du B, Qu D, Xiong W, Yin M, Ren X, Wang F, He J, Zhang B: MicroRNA-192 targeting retinoblastoma 1 inhibits cell proliferation and induces cell apoptosis in lung cancer cells. Nucleic Acids Res 2011, 39(15):6669-6678

30. Xiong S, Zheng Y, Jiang P, Liu R, Liu X, Chu Y: MicroRNA-7 inhibits the growth of human non-small cell lung cancer A549 cells through targeting BCL-2. Int J Biol Sci 2011, 7(6):805-814.

doi:10.1186/1746-1596-9-143

Cite this article as: Ning et al:: MicroRNA-182 modulates chemosensitivity of human non-small cell lung cancer to cisplatin by targeting PDCD4. Diagnostic Pathology 2014 9:143. 